\title{
Bull Terrier
}

National Cancer Institute

\section{Source}

National Cancer Institute. Bull Terrier. NCI Thesaurus. Code C53736.

The Bull Terrier is a thick-set muscular, well-proportioned animal with a short, dense coat that comes in pure white, black, brindle, red, fawn and tri-color. Its most distinctive feature is its head, which is almost flat at the top, sloping evenly down to the end of the nose. Standard Bull Terrier Height: 20-24 inches (51-61 cm.) Weight: 45-80 pounds (2036 kg.) Miniature Bull Terrier Height: 10-14 inches (25-33 cm.) Weight: up to 24-33 pounds (11-15 kg.) 